\title{
EL FONDO TEOLÓGICO DE LA LITERATURA URUGUAYA A PRINCIPIOS DEL SIGLO XX. LA ARMONÍA SEGÚN J.E. RODÓ Y H. QUIROGA
}

\author{
Maksymilian Drozdowicz \\ WSB Universidades, Wrocław \\ https://doi.org/10.18778/8220-195-6.17
}

\begin{abstract}
Resumen
El presente estudio se inscribe en un proyecto de investigación más amplio dedicado a la búsqueda de huellas teológicas en la literatura rioplatense a partir de la creación del Virreinato de La Plata hasta la época moderna. Descubrimos que en la literatura de los dos autores uruguayos, José Enrique Rodó (1871-1917) y Horacio Quiroga (1878-1937), es posible distinguir posturas cercanas a la visión optimista del mundo a pesar de las amenazas de la civilización de aquellos tiempos y una evocación constante de la religión cristiana como material de estudio, reflexión, pero también contemplación.
\end{abstract}

Palabras clave: José E. Rodó. Horacio Quiroga. Iglesia católica. Ética. Estética.

\section{1.}

\section{El optimismo de Rodó}

El siglo XX se inicia con la llegada del positivismo, influido por Bergson, Brentano, Husserl y el neotomismo, por Ortega y Gasset. Se nota el nacimiento de las nuevas posiciones contemporáneas: el socialismo, el marxismo y la corriente política de inspiración 
cristiana. En Uruguay aparece José E. Rodó, quien con su obra marca el paso del positivismo al neoespiritualismo, y como tal, es con razón denominado organizador de un modo de pensar metafísico en el Río de la Plata. (Fernández Moreno, 1975: 8) Debido a una política agresiva de los Estados Unidos, Rodó opone en su Ariel (1900) el progreso de la cultura latinoamericana al materialismo del mundo anglo-sajón. En obras como Nuestra América (1903), del argentino Carlos Octavio Bunge, o de Pueblo enfermo (1909), del boliviano Alcides Arguedas, se comienza el análisis sistemático de la propia realidad, aunque, en el campo del pensamiento, Hispanoamérica sigue imitando a Europa. (Gómez-Martínez, 2008: 413)

Rodó proclama la adhesión a la fe católica y atribuye el cristianismo como un marco imborrable de la hispanidad. Lo vemos a partir de sus textos, en los que evalúa y actualiza la herencia espiritual de España empapada del catolicismo. (Navascués, 1996: 371) José Enrique Rodó, dirigiéndose a las generaciones jóvenes, en su Ariel propone ver su situación en la perspectiva bíblica, argumentando que el cristianismo mismo se caracteriza por una juventud que es la del alma, lo que en suma, equivale a vivir el sueño, la gracia, el candor. El seguimiento a Jesús tiene este encanto peculiar como un aroma amoroso, ya que tras Jesucristo se desprende el aire de boda. (Rodó, 2003: II) El idealismo optimista paradógico de este intelectual une lo ético con lo estético e, interpretando de un modo bastante propio el kerygma evangélico, descubre que "virtud [misma] es también un género de arte, un arte divino". El arte comprometido no es todavía relacionado con la suerte del pobre y oprimido, según los argumentos tardíos de un Freire o un Gutiérrez, sino aún implica un imperativo actante kantiano: la enseñanza de lo bello contiene el bien que se traduce en el deber. La idea de la obligación moral es obvia por sí misma, se hace realidad y la más alta poesía. Aprovechándose de los conceptos de Kant, Rodó ofrece para la humanidad una solución optimista en respetar la ley moral que debería convertirse en una "estética de la conducta". Entonces, cada hombre intuirá el bien, su objetivo, distinguirá entre lo malo y bueno, bello y feo y lo bello sería fuente de armonía. De Kant viene el estoicismo que no 
debe ser una imitación sino más bien inspiración para el espíritu de la ética, resumido en el dicho del famoso filósofo: "Dormía, y soñé que vida era belleza; desperté y advertí que ella es deber [...]". (Rodó, 2003: IV)

De las palabras rodonianas se desprende el optimismo, la alegría y casi la dicha por haber descubierto una clave sencilla, pero impactante para hacer llegar sus palabras a los corazones de la juventud - el grupo predilecto del docto uruguayo. Él atrae mostrando lo atractivo de sus palabras que es el mismo mensaje evangélico. Y es verdad que ya en la Antigüedad se habían preocupado por acrecentar los valores humanos, perfeccionarse, ejercitarse en la resistencia, el estoicismo y la serenidad. Pero el cristianismo significa un paso más adelante en el perfeccionamiento moral. Dice Rodó que "el ideal cristiano se reconcilia de nuevo con la serena y luminosa alegría de la antigüedad”. (Rodó, 2003: IV) La civilización griega y romana son como gérmenes de los mejores valores para los pueblos circundantes y, por esta misma razón el cristianismo pone cimientos para los valores cada vez más perfectos, como igualdad. El sentido del orden, de la jerarquía y el respetar al genio nace de las civilizaciones clásicas, pero es el cristianismo el que insiste en acabar con el "desdén de los humildes y los débiles", propio de los aristócratas. Lo antiguo y lo cristiano se sintetiza en una oferta nueva para el porvenir, siendo el resultado de ambos la democracia que -según el autor uruguayo- "habrá triunfado definitivamente", sobre todo en el gran país del Norte que, sin embargo, empieza a amenazar a los países latinos, por lo cual surgen "las protestas airadas y las amargas melancolías" de los que ven la injustica disfrazada muchas veces de altruismo. Es necesario, pues, cultivar el arte, ya que su ensueño hace el alma más delicada y hace tal toda la vida, como lo experimentaban las viejas aristocracias de antaño. Estas flores del arte, estas élites selectas orteguianas que son sabedores del arte, pronto pueden marchitarse si, otra vez evocando a Ortega y Gasset y sus masas rebeldes, el ambiente se llenará de "la vulgaridad" y de "las impiedades del tumulto”. (Rodó, 2003: V) El arte requiere, pues la tranquilidad y silencio, apto para la contemplación. 
El ensayista uruguayo ve por doquier las "semillas" dispersas del Evangelio, propone este punto de vista teológico avant la lettre. Dice que se prefigura el Evangelio en los valores de los pueblos de la Antigüedad, en "la delicadeza de los escitas", en "la inteligencia a los beocios", también, en el "desinterés a los fenicios". (Rodó, 2003: VII) Rodó idea, pues, a su Ariel como respuesta a las urgencias de su tiempo, una forma del "excelso coronamiento" de la obra de la creación y este proceso es una forma de ascender hacia las formas más organizadas, desde lo primitivo hacia lo civilizado, si usar la terminología de Sarmiento. Y estas formas más organizadas, para valer más, deben tener "la llamarada del espíritu", lo que indudablemente tiene asociaciones pentecostales. Estas formas más organizadas, estos humanos con espíritu elevado ya se convierten en algo sublime: se inspiran noblemente en el pensamiento (y no en el instinto, añadamos), tienen "buen gusto en arte, heroísmo en la acción, delicadeza en las costumbres" que sobrepasan la barbarie y el humo asfixiante de las batallas. Como Fénix de sus cenizas, Ariel sale vencedor, siendo un nuevo Job, que experimentó el estiércol y el anonadamiento pero que resurge con orgullo y ya tiene una vida inmortal. (Rodó, 2003: VIII)

Ariel representa "la parte noble y alada del espíritu", combina perfectamente "el imperio de la razón y el sentimiento sobre los bajos estímulos de la irracionalidad", contagia el entusiasmo que debería ser siempre el móvil de cada acción. Con el entusiasmo juvenil debe llenar también la cultura, espiritualizándola, vivificándola y brindándole "la gracia de la inteligencia", como resume Mariana Alvarado (2003: 157). María Eugenia Vázquez Semadeni, haciendo la relectura del fragmento del capítulo III de Ariel: "Yo os ruego que os defendáis, en la milicia de la vida, contra la mutilación de vuestro espíritu por la tiranía de un objetivo único e interesado", descubre que Rodó en la figura del elfo ofrece un tipo de escudo espiritual "para defenderse del avance del utilitarismo calibanesco". (Vázquez Semadeni, 2007: 35) Ver la materia, tener los ojos puestos en lo económico, amasar fortuna olvidándose del alto vuelo del espíritu ético - estos son los temas que marcan la reflexión del autor uruguayo. El defender los valores presentes en su ensayo, la juventud latinoamericana, consciente de su "herencia 
de raza, una gran tradición étnica" (Rodó, 2003: VI), debe unirse, mantener aquel "vínculo sagrado de América Latina", pero sin encerrarse, sin construir trincheras que negarían el cosmopolitismo. Ariel es entonces el símbolo de un proyecto político-cultural que acentúa los valores tanto espirituales como religiosos (Vázquez Semadeni, 2007: 36-37)

El pensamiento rodoniano tiene una doble dimensión. Por un lado, supone la existencia de un proyecto utópico llamado la identidad latinoamericana; un ideal que alcanzar construido a base de la cultura sostenida por la historia colonial, la herencia hispánica (la lengua, la religión, las costumbres), cuyo principal elemento es la espiritualidad. Pero de estas realidades no pueden ser conscientes del todo las personas comunes, de poca orientación en la materia, iletradas, por lo cual la intención del ensayista fue acercarse a las élites. La doctrina arielista tiene el carácter positivo, porque no pretende construir la identidad latinoamericana en función de la negación de no ser los Estados Unidos. El mensaje arielista es, por tanto, cauteloso y moderado, llamado más tarde el "Evangelio de la Esperanza”. (Vázquez Semadeni, 2007: 38-39) Tal planteamiento no fue ni suficiente ni consolador para la próxima onda, la marxista, representada por tales autores latinoamericanos como José Carlos Mariátegui y Fernando Díez de Medina, comprometidos con el indigenismo y los grupos populares. Gracias a su postura firmemente antielitista, empieza el ocaso de la atractividad del arielismo acusado de idealista. (Vázquez Semadeni, 2007: 40) Rodó ha dejado de ser instructor de las juventudes del continente cuando estas entraron en los intereses dispares. El eclectismo e intelectualismo no fue bien recibido por las generaciones posteriores surgidas del campesinado y la clase media urbana. El ideal rodoniano de unir los extremos no fue posible en los tiempos de la lucha de clases y del ateísmo reinante y de la desconfianza marxista frente a las estructuras opresoras. Esta combinación de ética y estética no resultó transcendente; el panorama intelectual empieza a complicarse. Se olvida de la herencia lingüística, religiosa o espiritual y se empieza a cuestionar la misma identidad del continente. (Vázquez Semadeni, 2007: 45) 
2.

\section{La armonía de Quiroga}

El bien conocido cuentista uruguayo, Horacio Quiroga, autor del Decálogo del perfecto cuentista (1927) admiraba la poesía de Leopoldo Lugones a quien consideraba como maestro y amigo. Arturo García Ramos pone de manifiesto que la obra de Quiroga es multiforme y pasa aproximadamente por tres estadios: el que sigue a Poe (el mundo de horror y del más allá), el fantástico de la selva a lo Kipling (el conocimiento mágico de la naturaleza, su estudio y la lucha contra ella) y el realista a lo Chéjov. (García Ramos, 2010: 73) Además, Maupassant propone la desconfianza ante sí mismo y el miedo al otro. Pero la muerte, la locura y la selva fueron experiencias vitales propias solo de Quiroga, donde lo vivido se impone sobre lo escrito. (García Ramos, 2010: 96) Quiroga en los años bonaerenses empieza a distanciarse de su maestro y prescinde del elemento fantástico en sus relatos y de la perspectiva privilegiada desde afuera, prefiriendo adentrarse más en los sentimientos del individuo, como lo hace en cuentos como "La insolación" y "El alambre de púa", escritos completamente desde el punto de vista de animales. Gracias a Lugones obtiene el interés por los temas americanos y contemporáneos, introduciendo también nuevos inventos tecnológicos y aprovechando la fantástica europea ${ }^{1}$. (Speck, 1976: 425-425) El autor uruguayo se abre a nuevos horizontes que puede expresar a través de su narrativa: imitaciones de crónica, artículos de costumbres, cuentos realistas, cuentos fantásticos, cuentos largos que se aproximan a novelas cortas, o cuentos - casi poemas en prosa. (García Ramos, 2010: 69) Respecto a la actitud quiroguiana frente a las cuestiones religiosas y sus posibles inquietudes éticas, conviene dar el ejemplo de una carta dirigida a Ezequiel Martínez Estrada donde narra su experiencia con los peones del lugar. Ellos le critican cuando él mismo se pone a trabajar con ellos, viendo en este hecho una amenaza de perder la fuente de ingreso:

1 Speck afirma que Quiroga, igual que Borges, reconocía en Lugones su deuda. 
Yo robo, pues, el trabajo a los peones. Yo no tengo derecho a trabajar; ellos son los únicos capacitados. Son profesionales, usufructuadores exclusivos de un dogma. Tan bestias son, que en vez de ver en mí un hermano, se sienten robados. [...]. El único trabajador que lo ama, es el aficionado. Y éste roba a los otros. (Quiroga, 1987: 48)

Reconoce que hay una reivindicación de trabajo justa y, al desobedecer el reclamo popular, el escritor corre el riesgo de perder los lazos amistosos que se están formando a través del trabajo. En este aspecto Quiroga se acerca mucho al anarquista español-paraguayo, enemigo de la propiedad privada, Rafael Barrett (1876-1910)2.

El narrador de Quiroga, igual que su alter ego, siente no poseer una fe profunda. En el cuento "Pasado amor", de 1929, leemos sobre la desesperación de Morán que prevé su muerte cercana, sin consuelo: "Deseó, ofreció, confió su vida trunca a una felicidad redentora: La religión, más fuerte que un grande y puro amor, se lo había negado", por lo tanto, también la tumba misma también aparece como muerta, "fiel y fatal como la religión". Su destino, tantas veces invocado y que sigue la pista lugonesiana, parece sin embargo fatal, también frente a "una invencible Divinidad". (Quiroga, 1987: 51) Se desprende de esta parte la tristeza, desconfianza y el sentido crítico, cuando la divinidad, en vez de ser portadora de la dicha, se convierte en algo temible, tal vez en un tremendum et fascinosum de Rudolf Otto. Ezequiel Martínez Estrada reconoce la condición de fugitivo de la vida en Quiroga, oculto en la selva, sin biblioteca, vestido y sintiéndose pobre, "con ropas y calzado de pobre, remendadas por él muchas veces, intoxicándose con tabaco ordinario" (Quiroga, 1987: 53), no se convierte en anacoreta porque le faltan fuerzas y motivaciones para ello. Quiroga se sentía rico, al estar unido a la naturaleza, "en posesión de bienes que le pertenecían por derecho natural, y tenía muy clara conciencia de ello", luchando para alcanzar una postura estoica, la proclamada más tarde por Ricardo Güiraldes en Don Segundo Sombra - la

2 Sobre la importancia de la figura de Rafael Barrett para las letras paraguayas véase Drozdowicz (2013). 
impasibilidad frente a las alegrías y penurias. Como agnóstico, pretendía, sin embargo, vivir un ideal de asceta. Sus críticos expresan su tranquilidad por haber logrado algo de lo recomendado por Jesús: "En este sentido también era un asceta de la vida (como fue un misionero y un mártir). A su modo, cumplió el precepto evangélico de no dar al César lo que es de Dios". (Quiroga, 1987: 53) Quiroga encarna la fatalidad de la tragedia antigua al quedarse pendiente de la implacable lógica de la naturaleza, "nunca satisfecha de sacrificios crueles y de sangre", aproximándose casi a los dioses aztecas, como observa Luis Emilio Soto. Sus personajes quedan bloqueados por el bosque, se defienden y mueren sin escuchar las voces de socorro. (Quiroga, 1987: 54)

La selva, la región alejada de la civilización, no es propicia para el adoctrinamiento. Los personajes viven allá según sus costumbres y solo intuyen la ética, sin ser interrogados o molestados por ello. Alguna vez puede ocurrir la visita de un pastor de almas. En el cuento "Europa y América", que forma parte de Cuentos no recopilados en libro (1899-1935), el cura italiano de familia española Salvador Pedro, llega a Dolores inocente e ingenuo y, sintiéndose en pleno derecho de hablar, corrige y amonesta a los habitantes de la casa, aunque él mismo "se sabía ignorante", pero creyendo firmemente "en la misión de su sotana negra" (Quiroga, 1997: 264). El dueño, después de haber escuchado pacientemente las palabras del cura, le replica a quemarropa:

- Bueno, ahora hablo yo. Vea, señor: aquí en América, sobre todo en mi casa, sobre todo yo, uno hace justamente aquello que tiene ganas de hacer, y nos parece siempre de la más mala educación dar consejos cuando no se nos pide, como el señor cura ha tenido el mal gusto de hacerlo. Por gracia de Dios, que está en mí, aunque usted no crea, sé desde hace muchos años lo que debo hacer, aunque lo haga mal [...]. (Quiroga 1987: 265)

Este desencuentro pastoral, muy llamativo, expresa que las palabras de afuera no se acomodan a la cruda realidad misionera. La superioridad del dueño proviene, pues de una moral que no quiere sentirse inferior a la doctrina oficial. La misma actitud la 
observamos entre los campesinos de Itapé de Hijo de hombre, de Augusto Roa Bastos.

Quiroga retirado y olvidado desarrolla los valores como la trabajosidad o el aguante. Siendo mal comerciante (casi todas sus empresas económicas como el cultivo de yerba mate, la producción del licor de naranjas, etc. fracasaron), como escritor muestra mucha sensibilidad y vitalidad. En opinión de sus peones era "un hombre extremadamente sobrio y trabajador" (Rodríguez, 1975: 32). Luchando contra las adversidades logra forjar en sí mismo una personalidad sólida, "Quiroga ama y conoce la naturaleza como por un desafío hecho contra sí mismo" - dirá Noé Jitrik. (Rodríguez, 1975: 34) La convivencia constante con el paisaje produce en él un goce espiritual innegable e inmenso. Antonio Hernán Rodríguez no intenta llamar esta experiencia "mística", porque es demasiado fácil caer en la tentación en este aspecto. Más bien su modo de vivir linda "en ocasiones con una profunda serenidad de alma” (Rodríguez, 1975: 34), que todavía no equivale al estado de la santidad, imprescindible para místicos.

¿Se sentía Quiroga fugitivo y exiliado en su casita de Misiones? Rodríguez demuestra que al contrario, no cabe duda de que en "la ciudad se sentía Quiroga un desterrado, y precisamente allí, en el Hospital de Clínicas, más que nunca”, cuando se curaba de cáncer de próstata, porque fue un destierro de su "mundo ideal en el que llegó a ser feliz, o por lo menos de una tierra trabajada por sus propias manos - por sobre todas las miserias humanas" (Rodríguez, 1975: 52). Paradójicamente, es ahí donde le consideraban "perdido", pero donde, en Misiones, igual que Rimbaud o Darío en sus patrias respectivas, se creó una leyenda vital en términos estéticos-como dice Álvaro Salvador-, y logró convertir "la vida en poesía". (Quiroga, 2010: 14-15) Este crítico considera como clave de su lógica el "esteticismo moral", que se fundamenta en cierta dosis del formalismo kantiano, pero también en obedecer a la concepción romántica propia del luteranismo, que combinaría la voluntad de la naturaleza de Schopenhauer con la voluntad de poder y de superarse de Nietzsche (Quiroga, 2010: 15, nota 8).

En 1906, Horacio Quiroga escribe a José María Fernández Saldaña, de Buenos Aires, que se siente feliz por no compartir 
polémicas, por no tener el contacto con la religión porque prefiere la libertad, mientras que en la metrópoli „,[h]e leído que por ahí andan de líos religiosos". (Quiroga, 2010: 221) La selva, pues, ofrece el aislamiento, trae la paz si uno la busca. A veces la felicidad consiste en vivir con conciencia tranquila, sin grandes pretensiones, resumida por ejemplo en las palabras del cuentista dirigidas a José María Fernández Saldaña a finales de septiembre de 1909: "Confío como en Mahoma en el matrimonio y la vida en Misiones. Con mi mujer, tal como la quiero y me entiende, y con unos cuantos pellejos de víbora a romper por ahí, la cosa va”. (Quiroga, 2010: 260) Si no hubiéramos conocido el trágico desenlace de la vida familiar misionera de Quiroga (el suicidio de su esposa incluido), parecería que tenemos un cuadro casi sacado de "La vida retirada" de un Fray Luis de León sudamericano. Al leer la obra Brand, de Ibsen, el cuentista confiesa a Martínez Estrada, en 1936, un año antes de su muerte, echar de menos el ideal de Jesús: "Y oiga usted un secreto: yo, con más suerte, debí haber nacido así. Lo siento en mi profundo interior" (Quiroga, 2010: 586) La situación de este escritor es, por tanto, parecida, a la de Simone Weil, de la que se ha dicho que "permaneció en el umbral de la Iglesia".

\section{3.}

\section{Conclusión}

Releyendo la obra de estos dos personajes de la primera mitad del siglo XX, José Enrique Rodó y Horacio Quiroga, descubrimos que ambos pertenecen a la época cuando todavía importaba la religión como punto de referencia. Rodó reinterpreta la Biblia, y sobre todo el mensaje evangélico de Jesús, para difundir el optimismo que tanto faltaba en el continente sumido en el terror, y Quiroga ofrece la huida como respuesta a la realidad que acosa, para poder encontrar las respuestas vitales. Alejándose mucho, el cuentista y el ensayista, sin darse cuenta, rozan con el optimismo paradójico al lanzar la idea del arte que libera; el arte que equivale a ethos. 


\section{Bibliografía}

Aínsa, F. (1986). Identidad cultural de Iberoamérica en su narrativa. Madrid: Editorial Gredos.

Alvarado, M. (2003). "Rodó y su Ariel. El Ariel de Rodó", Cuyo. Anuario de Filosofía Argentina y Americana, 20, 155-173, [en línea] <http://bdigital.uncu.edu.ar/objetos_digitales/228/ alvaradoCuyo20.pdf $>$ [13.05.2018].

Drozdowicz, M. (2013). Anarquistas y esclavos. Reminiscencias barrettianas en la literatura paraguaya (1940-1990). Ostrava: Filozofická fakulta OU.

Dussel, E. (1992). Historia de la Iglesia en América Latina: medio milenio de coloniaje y liberación (1492-1992). Madrid: Mundo Negro-Esquila Misional, [en línea] <http://biblioteca.clacso.edu.ar/clacso/otros/20120215100901/iglesia.pdf > [13.12.2016].

Elbanowski, A. (2013). Świadectwa, metafory, fabulacje: wspótczesna literatura Ameryki Łacińskiej. Warszawa: CESLA.

Fernández Moreno, C. (1975). “¿El más grande metafísico del Plata?”. Revista de la Universidad de México, 10, 1-12.

García Ramos, A. (2010). El cuento fantástico en el Río de la Plata. Madrid: Editorial La Mirada Malva.

Gómez-Martínez, J.L. (2008). "Pensamiento hispanoamericano del siglo XIX”, en L.I. Madrigal (coord.). Historia de la literatura hispanoamericana. T. II. Del neoclasicismo al modernismo, 399-415. Madrid: Cátedra.

Martínez, E. (2010). "Prólogo. Quiroga y el terror a la intimidad", en H. Quiroga, Quiroga íntimo. Diario de viaje a París, 9-51. Madrid: Editorial Páginas de Espuma.

Navascués, J. de (1996). "Imagen de Iglesia en la literatura en la literatura hispanoamericana contemporánea”, en J.-I. Saranyana et al. (eds.). ¿Qué es la historia de la Iglesia? XVI Simposio Internacional de Teología, 367-384. Pamplona: Ed. Universidad de Navarra - EUNSA.

Quiroga, H. (1987). Quiroga por Horacio. Montevideo: Departamento de Producción Gráfica y Audiovisual - MEC.

Quiroga, H. (1997). Cuentos completos II. Buenos Aires: Seix Barral. 
Quiroga, H. (2010). Quiroga íntimo. Diario de viaje a París. Madrid: Editorial Páginas de Espuma.

Rodó, J.E. (2003). Ariel, [en línea] <www.biblioteca.org.ar/libros/70738.pdf> [29.10.2017].

Rodríguez, A.H. (1975). El mundo ideal de Horacio Quiroga. Y cartas inéditas de Quiroga a Isidoro Escalera. Posadas: Centro de Investigación Científica-Cultural - Instituto Superior del Profesorado "Antonio Ruiz de Montoya".

Speck, P. (1976). "Las fuerzas extrañas, Leopoldo Lugones y las raíces de la literatura fantástica en el Río de la Plata”, Revista Iberoamericana, 42.96, 411-426.

Vázquez Semadeni, M.E. (2007). “Ariel y la pregunta por la identidad latinoamericana", Latinoamérica. Revista de Estudios Latinoamericanos, 45, 31-58 [en línea] <http://www.redalyc.org/ articulo.oa?id $=64011417003>[15.05 .2018]$. 